\title{
Efeitos do Uso do Brinquedo Terapêutico no Comportamento de Crianças Durante o Tratamento Quimioterápico
}

\author{
Portela, Odete Teresinha; Santos, Edson Silva dos; Dutra, Larissa Veríssimo; \\ Carmagnani, Maria Isabel Sampaio; Filipini, Rosângela; Gomes, Gilson Moreira \\ Hospital São Paulo, Universidade Federal de São Paulo — odete.portela@unifesp.br
}

Introdução: o câncer modifica a vida da criança e sua família, resultando sofrimento, por isso, exige a escolha de estratégias diversas no cuidado. o uso do brinquedo terapêutico (BT) tem sido uma prática amplamente utilizada e com bons resultados; técnica baseada nos princípios da ludoterapia, a fim de aliviar ou diminuir a ansiedade da criança que esteja ou não hospitalizada. Ele tem sido uma excelente estratégia de cuidado humanizado, portanto, aplicável a crianças em tratamentos invasivos, como a quimioterapia. Objetivo: Verificar os efeitos do BT nas reações adversas e comportamento em crianças durante seções de quimioterapia (QT). Método: Estudo descritivo, realizado com 17 crianças de 4 a 10,9 anos, de ambos os sexos, em início de tratamento oncológico num hospital da Grande São Paulo, no período de janeiro a abril de 2012. Foi aplicada a técnica do BT ao início do tratamento de QT; seguimento das crianças durante cinco dias de tratamento, observando-se os efeitos das reações adversas das drogas e seu comportamento. Foi utilizado um instrumento validado para avaliação do comportamento, o modelo de RIBEIRO; SABATÉS e RIBEIRO, 2001. Realizado análise descritiva dos dados por meio do Epi-Info, 6.0. Resultados. a média de idade foi 7,5 anos; predomínio de meninos (64,7\%); e maioria com renda baixa. no processo de hospitalização, 6 (35,3\%) tiveram sua primeira experiência e a média foi 3 internações. As leucemias representaram $76,5 \%$ das ocorrências de câncer, seguidas dos Linfomas $(11,8 \%)$. Quanto ao tratamento, à via escolhida para a administração das drogas mais utilizada foi à endovenosa, com $100 \%$ dos casos, paralelamente com a via oral, em $88,2 \%$. As drogas mais utilizadas foram os antimetabólicos e os antibióticos, ambos em $70,6 \%$ dos casos. Durante as cinco sessões de QT, houve diminuição de náusea, vômito, mal estar, adinamia e agitação, após o primeiro dia. na somatória total dos oito efeitos observados, a redução também foi elevada ( $82,4 \%$ no primeiro dia e $29,4 \%$ no terceiro); destaca-se a diminuição da soma do escore de comportamento (5 para 3). Conclusão. a criança ao receber um diagnóstico de câncer fica exposta a uma situação estressante que se soma à possibilidade de internação. Ela deve adaptar-se a novos horários, conviver com pessoas desconhecidas, submeter-se a procedimentos invasivos, permanência hospitalar prolongada no quarto, enfim, situações que resultam na diminuição do brincar, antes rotineiras na vida da criança. Esta circunstância interferem no convívio social, no seu desenvolvimento cognitivo, além de aumentar o nível de dependência pelo cuidador, assim, acentua-se sua vulnerabilidade. o uso de estratégias de cuidado com a criança, como o brinquedo terapêutico contribui no tratamento, amenizando o sofrimento e comportamento mais seguro. PALAVRAS CHAVES - Criança, câncer, brinquedo e Terapia

Portela, Odete Teresinha; Santos, Edson Silva dos; Dutra, Larissa Veríssimo; Carmagnani, Maria Isabel Sampaio; Filipini, Rosângela; Gomes, Gilson Moreira. Efeitos do Uso do Brinquedo Terapêutico no Comportamento de Crianças Durante o Tratamento Quimioterápico. In: Anais do Congresso Internacional de Humanidades \& Humanização em Saúde [= Blucher Medical Proceedings, num.2, vol.1]. São Paulo: Editora Blucher, 2014. ISSN 2357-7282 DOI 10.5151/medpro-cihhs-10559 